\title{
A poesia de Manuel de Barros: entre o regional e o universal
}

Adilson Citelli*

Graduado em Letras (1973), mestre em Literatura Brasileira (1982) e doutor em Literatura Brasileira (1990), todos pela Universidade de São Paulo. É professor titular do Departamento de Comunicações e Artes da ECA/USP e dos programas de graduação e pós-graduação, onde ministra cursos e orienta dissertações e teses nas áreas de Comunicação e Linguagem, com ênfase nas subáreas: Comunicação/Educação, Comunicação/Linguagem. É coeditor da revista Comunicação \& Educação**.

E-mail: citelli@uol.com.br

Manoel Wenceslau Leite de Barros nasceu no dia 19 de dezembro de 1916, à beira do rio Cuiabá (MT). Morou também em Corumbá (MS) e no Rio de Janeiro. Atualmente, vive em Campo Grande (MS).

Seu pai, João Venceslau Barros, possuía uma fazenda no Pantanal, onde o menino Manoel, carinhosamente chamado de Nequinho, cresceu brincando. Frequentou colégio interno aos 8 anos em Campo Grande e, depois, no Rio de Janeiro. Não gostava de estudar até descobrir os livros do Padre Antônio Vieira: "A frase para ele era mais importante que a verdade, mais importante que a sua própria fé. O que importava era a estética, o alcance plástico. Foi quando percebi que o poeta não tem compromisso com a verdade, mas com a

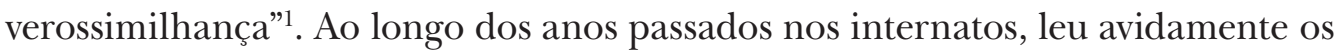
clássicos atentando para a escrita e as estratégias narrativas por eles produzidas.

Logo que deixou o colégio, Manoel de Barros leu Une Saison en Enfer, de Arthur Rimbaud, verificando que a produção do poema poderia resultar de jogos sinestésicos, com forte mistura entre percepções afeitas a sentidos diferentes - a cor que evoca a imagem, o som capaz de evidenciar o aroma etc. Engajou-se politicamente e entrou para a Juventude do Partido Comunista Brasileiro. Como havia pichado o slogan "Viva o comunismo" numa estátua, no momento em que ia ser preso pela polícia, a dona da pensão onde morava intercedeu pelo jovem publicista. O policial soube que o rapaz tinha escrito um livro e levou o único exemplar de Nossa Senhora de minha escuridão com ele, em troca da liberdade do moço de 18 anos.

Após uma decepção com o líder comunista Luiz Carlos Prestes, quando este apoiou Getúlio Vargas, Manoel rompeu com o PCB e foi para o Pantanal. Pouco tempo depois, viajou pela Bolívia, pelo Peru e morou um ano em Nova

* Com a colaboração de Cristine Vargas (revista Comunicação \& Educação - ECA/USP e FFLCH/ USP).

** É autor de inúmeros artigos e livros, dentre os quais se destacam: Linguagem e persuasão (Ática, 1994); Comunicação e educação: a linguagem em movimento (SENAC, 2000); Palavras, meios de comunicação e educação (Cortez, 2006).

1. Manoel de Barros. Disponível em: <http:// www.releituras.com/manoeldebarros_bio.asp $>$. Acesso em 15 out. 2009. 
comunicação \& educação • Ano XIV • Número 3 • set/dez 2009

York, onde fez cursos no Museu de Arte Moderna. Nessas andanças, o escritor foi aprendendo o sentido de liberdade que começou a conhecer quando saiu do colégio, alimentando sua poesia com imagens e sempre se encantando com quadros e filmes. Ao retornar ao Brasil, conheceu a mineira Stella, com quem se casou em três meses. Dessa relação, que perdura até a atualidade, nasceram três filhos: João, Pedro e Marta.

Manoel de Barros escreveu o primeiro poema aos 19 anos e morou no Rio de Janeiro até terminar o curso de Direito, em 1949. O seu primeiro livro, Poemas concebidos sem pecado, foi feito artesanalmente por amigos, numa tiragem de 21 exemplares. Nos anos 1980, sua poesia começou a aparecer ao público através de nomes como Millôr Fernandes, Fausto Wolff e Antônio Houaiss. Hoje o poeta é reconhecido nacional e internacionalmente como um dos mais importantes do Brasil e mais originais do século.

Dentre os prêmios recebidos pelo poeta, encontram-se: Prêmio Orlando Dantas pelo livro Compêndio para uso dos pássaros, em 1960; Prêmio Nestlé pelo Livro sobre nada, em 1997; Prêmio Jabuti de Literatura, na categoria Poesia, com o livro O guardador de águas, em 1989.

\section{TRANSCENDENDO O ESPAÇO REGIONAL}

Manoel de Barros consolidou sua trajetória como escritor regionalista, mentor do espaço pantaneiro. Tendo diversos títulos publicados no Brasil e no exterior, no período de 72 anos (desde Poemas concebidos sem pecado, publicado em 1937, até Memórias inventadas III - A terceira infância, de 2007), é difícil definir uma produção tão extensa com uma característica estanque; contudo, não se pode ignorar que este traço regionalista de alcance universal constitui a base de sua obra, tornando-a peculiar. Dessa maneira, o que se busca neste breve espaço, a partir de uma pequena seleção de poemas, é esboçar algumas características particulares da obra de Manoel de Barros e pelas quais é frequentemente evocado. São elas: o regionalismo pantaneiro, o olhar infantil e o entortamento da linguagem, seguindo as palavras do próprio Manoel de Barros: "Gosto de furar gramáticas, de entortar sintaxes"2.

Analisando a obra de Manoel de Barros em seu início, nota-se que a primeira publicação, Poemas concebidos sem pecado, indica a busca de uma singularidade nos quadros de nossa literatura. O poema "Entrar na academia já entrei" exibe os conflitos experimentados pelo homem regional vivendo na cidade que, contra a sua vontade, ainda mantém os modos de bugre. O deslocamento expresso no poema traça a necessidade de um lugar intermediário para a solução do conflito. Em Gramática expositiva do chão, publicado em 1966, observa-se que o espaço, com elementos regionalistas, não é mais produtor de conflito, dando lugar ao

Manoel de Barros homenageado em Brasília. Disponível em <http:// noticias.terra.com.br/ imprime/0,01237576 El1538,00.html>. Acesso em 15/10/2009. lirismo. Na obra há poemas com notas explicativas que se constituem em outros poemas, entortando a linguagem ao romper com a estrutura poética usual.

Em etapa seguinte de sua obra, Manoel de Barros prossegue na construção de um espaço poético próprio. Em "Prefácio", de Concerto a céu aberto 
para solos de ave, de 1991, o poeta revela um mundo primevo, com elementos do pantanal tais como moscas e caranguejos; entretanto, estes referenciais são travestidos de uma aparência e providos de atitudes que só existem no mundo particular do sujeito poético. Na primeira parte do poema "Mundo pequeno", de $O$ livro das ignorãças, publicado em 1993, o nosso autor também descreve um universo à parte. Através da fabulação do real, feita a partir do olhar infantil, há a criação de um espaço particular mágico e fantástico. A infantilização é percebida, igualmente, pelo retorcimento da linguagem, ou seja, a inusitada troca das classes verbais, os substantivos que assumem função de verbos: "Quando o rio está começando um peixe, / Ele me coisa / Ele me rã / Ele me árvore...”.

Como última obra analisada, Ensaio fotográfico, publicado em 2000, exibe um espaço materializado através de imagens compostas pelo poeta-fotográfo. Para compreender tal abordagem, comparemos paralelamente os poemas " $\mathrm{O}$ poeta" e "Despalavra": enquanto o primeiro utiliza a metalinguagem como recurso e a perspectiva infantil como propulsora da vocação poética para explicar a passagem do elemento poemático à construção de imagens, o segundo relata a própria transposição: "Hoje eu atingi o reino das imagens, o reino da despalavra". Por fim, no poema "Borboletas" é flagrado o cenário produzido pelo poeta-fotógrafo, em que os elementos regionais do Pantanal ocupam todos os versos, materializando o espaço criado.

Embora os lugares descritos mobilizem características pantaneiras, transcendem o ambiente regional constituindo espaço super-regional. A expressão espaço super-regional foi utilizada por Antonio Candido para se referir à obra de Guimarães Rosa: "Entrando [...] pelo pitoresco regional mais completo e meticuloso, e assim conseguindo anulá-lo como particularidade, para transformá-lo em valor de todos" ${ }^{\text {" O }}$ O poeta utiliza suas raízes na construção de um ambiente particular, revestindo-as de lirismo, e, para tal, mobiliza, como ferramentas dessa construção, sobretudo, o olhar infantil, o entortamento da linguagem e, por vezes, a metalinguagem. A dimensão super-regional de Manoel de Barros se apresenta como superação do conflito campo versus cidade, posto a abrigar um ser que, ao mesmo tempo que não pertence ao mundo urbano, não se circunscreve ou se resume ao espaço de onde se origina. A invenção criativa permite reconhecer nos textos de Manoel de Barros esse elemento universalizador que matiza toda a grande criação poética.

\section{POESIAS}

Entrar na Academia já entrei

mas ninguém me explica por que essa torneira

aberta

neste silêncio de noite

parece poesia jorrando...

Sou bugre mesmo

me explica mesmo
3. ALVES, Rogério Eduardo. Manoel de Barros: o poeta fazendeiro. 2005. Dissertação (Mestrado)Faculdade de Filosofia, Letras e Ciências Humanas, Universidade de São Paulo, 2005. 
me ensina modos de gente

me ensina a acompanhar um enterro de cabeça baixa

me explica por que um olhar de piedade

cravado na condição humana

não brilha mais que anúncio luminoso?

Qual, sou bugre mesmo

só sei pensar na hora ruim

na hora do azar que espanta até a ave da saudade

Sou bugre mesmo

me explica mesmo

se eu não sei parar o sangue, que que adianta

não ser imbecil ou borboleta?

Me explica por que penso naqueles moleques

como nos peixes

que deixava escapar do anzol

com queixo arrebentado?

Qual, antes melhor fechar esta torneira, bugre velho...

(Poemas concebidos sem pecado)

Colear induz

Para rã

E caracol (2)

(2) O CARACOL - Que é um caracol? Um caracol é: / a gente esmar / com os bolsos cheios de barbante, correntes de latão / maçanetas, gramofones / etc. / Um caracol é a gente ser: / por intermédio de amar o escorregadio / e dormir nas pedras. / É: / a gente conhecer o chão por intermédio de ter visto uma lesma / na parede / e acompanhá-la um dia inteiro arrastando / na pedra / seu rabinho úmido / e / mijado [...]

(Gramática expositiva do chão)

\section{Prefácio}

Assim é que elas foram feitas (todas as coisas) sem nome.

Depois é que veio a harpa e a fêmea em pé.

Insetos errados de cor caíam no mar.

A voz se estendeu na direção da boca.

Caranguejos apertavam mangues.

Vendo que havia na terra

Dependimentos demais

E tarefas muitas -

Os homens começaram a roer unhas.

Ficou certo pois não

Que as moscas iriam iluminar 
O silêncio das coisas anônimas.

Porém, vendo o Homem

Que as moscas não davam conta de iluminar o

Silêncio das coisas anônimas -

Passaram essa tarefa para os poetas.

(Concerto a céu aberto para solos de ave)

\section{Mundo pequeno}

O mundo meu é pequeno, Senhor.

Tem um rio e um pouco de árvores.

Nossa casa foi feita de costas para o rio.

Formigas recortam roseiras da avó.

Nos fundos do quintal há um menino e suas latas maravilhosas.

Seu olho exagera o azul.

Todas as coisas deste lugar já estão comprometidas com aves.

Aqui, se o horizonte enrubesce um pouco, Os besouros pensam que estão no incêndio.

Quando o rio está começando um peixe,

Ele me coisa

Ele me rã

Ele me árvore.

De tarde um velho tocará sua flauta para inverter os ocasos.

(O livro das ignorãças)

\section{O poeta}

Vão dizer que não existo propriamente dito

Que sou um ente de sílabas.

Vão dizer que eu tenho vocação para ninguém.

Meu pai costumava me alertar:

Quem acha bonito e pode passar a vida a ouvir o som das palavras

Ou é ninguém ou é zoró.

Eu teria treze anos.

De tarde fui olhar a Cordilheira dos Andes que

se perdia nos longes da Bolívia

E veio uma iluminura em mim.

Foi a primeira iluminura.

Daí botei meu primeiro verso: 
Aquele morro bem que entorta a bunda da paisagem.

Mostrei a obra pra minha mãe.

A mãe falou:

Agora você vai ter que assumir suas irresponsabilidades.

Eu assumi: entrei no mundo das imagens.

(Ensaios fotográficos)

\section{Despalavra}

Hoje eu atingi o reino das imagens, o reino da despalavra.

Daqui vem que todas as coisas podem ter qualidades humanas.

Daqui vem que todas as coisas podem ter qualidades de pássaros.

Daqui vem que todas as pedras podem ter qualidades de sapos.

Daqui vem que todos os poetas podem ter qualidades de árvores.

Daqui vem que os poetas podem arborizar os pássaros.

Daqui vem que todos os poetas podem humanizar as águas.

Daqui vem que os poetas devem aumentar o mundo com suas metáforas.

Que os poetas podem ser pré-coisas, pré-vermes, podem ser pré-musgos.

Daqui vem que os poetas podem compreender o mundo sem conceitos.

Que os poetas podem refazer o mundo por imagens, por eflúvios, por afeto.

(Ensaios fotográficos)

\section{Borboletas}

Borboletas me convidaram a elas.

O privilégio insetal de ser uma borboleta me atraiu.

Por certo eu iria ter uma visão diferente dos homens e das coisas.

Eu imaginava que o mundo visto de uma borboleta seria, com certeza, um mundo livre aos poemas.

Daquele ponto de vista:

Vi que as árvores são mais competentes em auroras do que os homens.

Vi que as tardes são mais aproveitadas pelas garças do que pelos homens.

Vi que as águas têm mais qualidade para a paz do que os homens.

Vi que as andorinhas sabem mais das chuvas do que os cientistas.

Poderia narrar muitas coisas ainda que pude ver do ponto de vista de uma borboleta.

Ali até o meu fascínio era azul.

(Ensaios fotográficos)

\section{REFERÊNCIAS BIBLIOGRÁFICAS}

ALVES, Rogério Eduardo. Manoel de Barros: o poeta fazendeiro. 2005. Dissertação (Mestrado)-Faculdade de Filosofia, Letras e Ciências Humanas, Universidade de

São Paulo, 2005. 
BARROS, Manoel de. Ensaios fotográficos. Rio de Janeiro: Record, 2000.

. Poemas concebidos sem pecado. 3. ed. Rio de Janeiro: Record, 1999.

. O livro das ignorãças. Rio de Janeiro: Record, 1993.

. Concerto a céu aberto para solos de ave. Rio de Janeiro: Civilização Brasileira, 1991.

Gramática expositiva do chão: poesia quase toda. Rio de Janeiro: Civilização Brasileira, 1990.

CANDIDO, Antonio. Literatura e subdesenvolvimento. In: A educação pela noite e outros escritos. São Paulo: Ática, 1987.

\section{Endereço eletrônico}

Manoel de Barros. Disponível em: <http:/ /www.releituras.com/manoeldebarros_ bio.asp>. Acesso em: 15 out. 2009. 


\title{
Novos olhares sobre a Literatura Infantil e Juvenil
}

\begin{abstract}
"O ideal da literatura é deleitar, entreter, instruir e educar as crianças, e melhor ainda se as quatro coisas de uma vez. [...]. Se não houver arte que produza o prazer, a obra não será literária e, sim, didática."
\end{abstract}

Lúcia Pimentel Góes

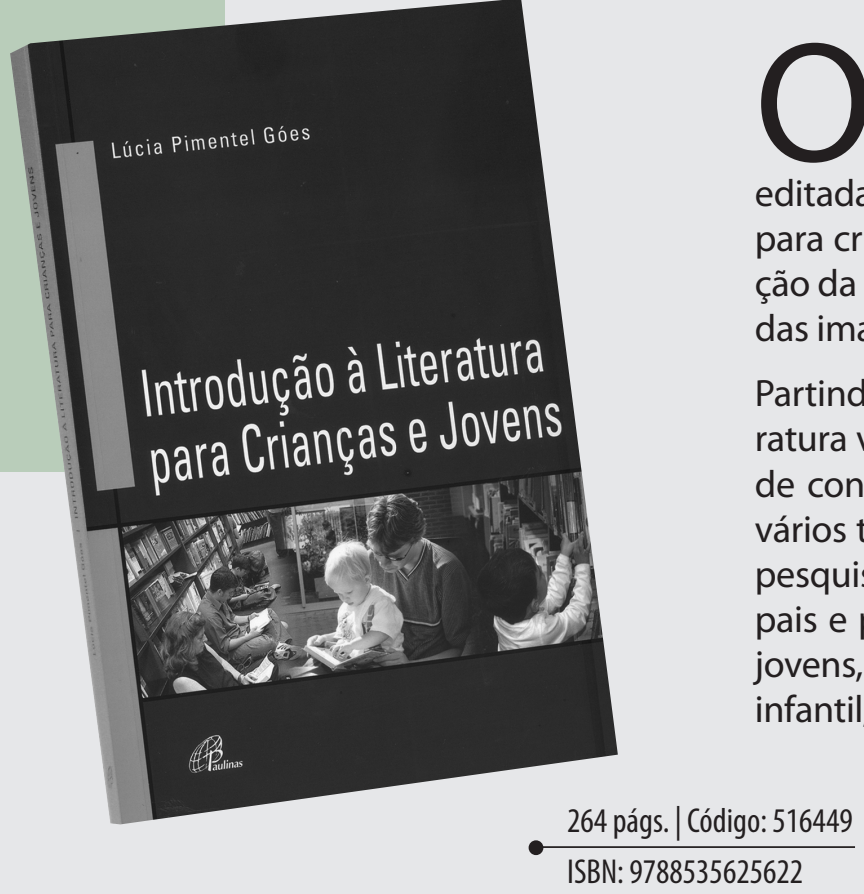

C om base em reflexões teórico-práticas sobre a premência de ressignificar Pedagogia e Arte, o livro da professora Maria Zilda da Cunha visa contribuir com a leitura crítica de obras de literatura infantil e juvenil para erigir critérios que possam balizar novas seleções, análises e a mediação do professor entre a criança e a literatura. Nesse sentido, nos oferece mais do que uma fundamentação teórica para a leitura, análise e crítica da produção literária em língua portuguesa para crianças e jovens de hoje.

Maria Zilda tece reflexões sobre a literatura do gênero, como fenômeno estético, considerando sua complexidade e intrínseca relação com a cultura, a história e a evolução social, perspectiva que a compreende neste mundo representado por novas tecnologias comunicacionais e mediado por novas formas de produção de linguagem. s livros para crianças e jovens são literatura? Têm um papel a desempenhar na formação intelectual e sensível da criança? Obra de Lúcia Pimentel Góes, agora repor Paulinas, descreve a função primeira da literatura para crianças e jovens, qual seja, estético-formativa, a educação da sensibilidade, que reúne a beleza da palavra e a beleza artindo da indagação sobre a existência ou não de uma Liteesquisadora Aborda elementos que merecem a atenção de pais e profissionais na escolha de obras para os pequenos e ovens, como qualidade, efeitos da leitura, desenvolvimento infantil, origem, histórico, tipos e gêneros de textos.

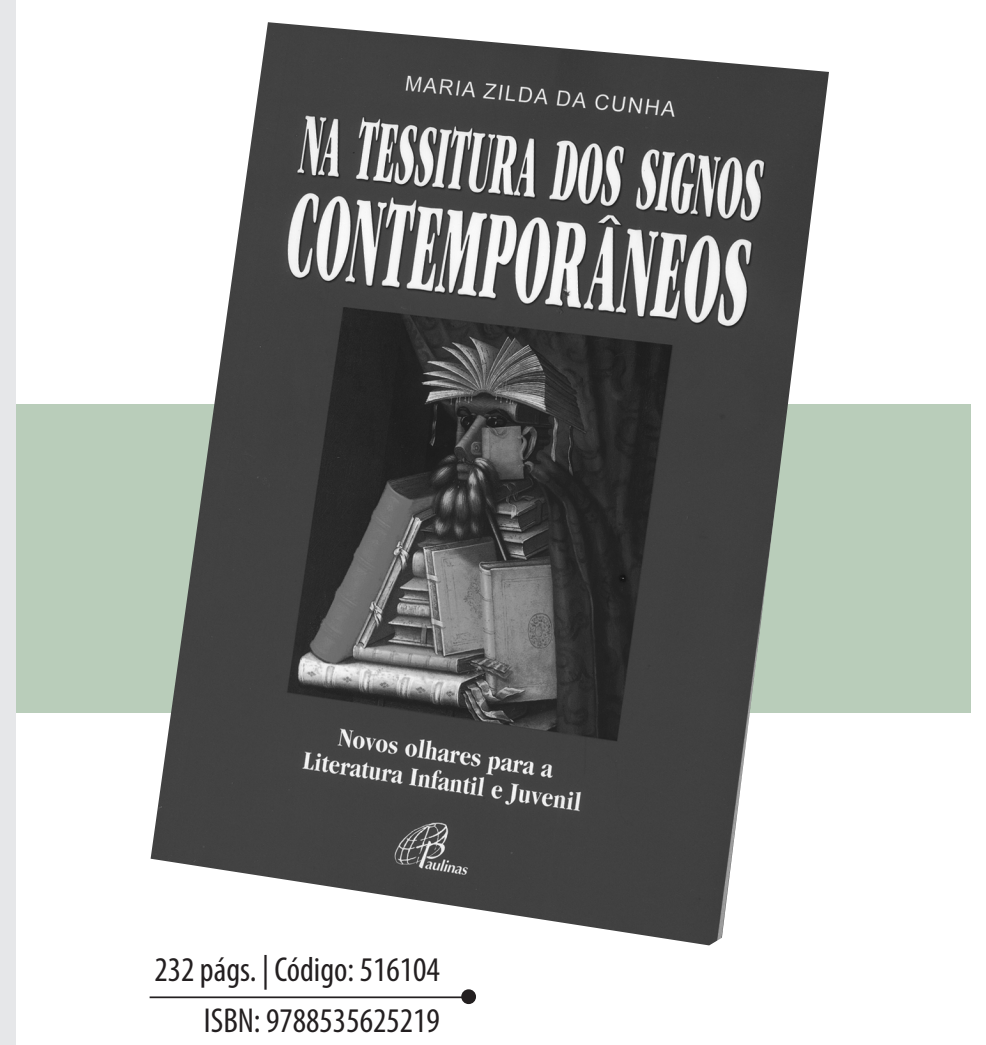

